\title{
局部加熱によるき裂の定量的非破壊評価*
}

\author{
坂 真 澄*1, 松 本 正 典*2
}

\section{NDE of a Crack by Local Heating with Laser Beam}

\author{
Masumi SAKA and Masanori MATSUMOTO
}

\begin{abstract}
A method was investigated for nondestructive evaluation of 2-D crack or slit depth by measurement of temperature difference between two points on the material surface in non contact. In the first, experiment was performed on the specimens of 304 stainless steel with a slit. Local temperature field around the crack or slit was formed by heating small area near the crack or slit with Nd: YAG laser beam, and temperature at a point was measured by infrared thermography. The slit depth was evaluated exactly by comparing experimental results with numerical analysis of non-steady heat conduction problem. Next similar experiment was carried out to evaluate the fatigue crack depth. However it was difficult to evaluate crack depth, because formed temperature field hardly changed either existence of the crack or not. So the effect of crack opening displacement on the temperature field was examined. It is shown that evaluating crack depth is possible by the present method, provided that load is applied to open the crack.
\end{abstract}

Key Words: Nondestructive Inspection, Numerical Analysis, Crack Opening Displacement, Thermal NDE, Crack Depth

\section{1. 緒}

種々の構造物の健全性涂価に破壞力学を適用する 際，き裂の定量的非破壊䛅価が不可欠である。近年の 赤外線センサの著しい進歩に伴い，温度計測の精度・ 空間分解能拀よび計測速度などに優れた高性能の赤外 線画像装置が開発されて抢り，温度や熱流束などの物 理菓を用いた熱的非破塤評価于法に関寺る研究が注目 されてきている，同手法においては，非接触による広 範四の領域を対象とした検揸への心们や非導電性材料 への適用などが期待されている。

例えば，Banks ら (1)は，裏面に腐食部を有する材料 をレーザや赤外線ランプで加熱したときの赤外線画像 装置による濫度分布計測に基づき，腐食部形状の最適 化手法による評価を行っている. Spicerら(2)はははく 離欠宿を有する被検查物の表面全体をレーザにより一 様加熱し，表面温度の時間変化を計測することにより 好材とコーティングの境界に抢ける接合の棓価を行っ ている。

* 原橧受付 1998 件: 3 月 26 月。

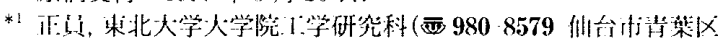
荒卷字消蕌 01)

*2 果北大等大学院
またき裂の熱的非破壇評価に関しては, 通電加熱に 上る材料表面上のき裂長さの評価(3)や通風加熱・高 周波加熱によるき裂の検出(4)など、赤外線画像装置を 用いた材料表面上の温度分布の特異部や不連続部の検 出によるき裂の検知に関する先駆的な報告がある。

一方, Saka ら (5) は, 熱的手法ではないが，き裂深さ の非破壊評価手法として，き裂の近傍に電位差計測端 子㧍よび電流入出力端子を配置した近接端子を用いる 直流電位差法に基づく手法を提案し，き裂から離れて 電流の入出力を行う従来法に比べ感度良くき裂深さの 評価が行えることを示した．電位場と温度場の類似性 より，同手法の応用による熱的手法によるき裂墚さの 非接触評価の可能性が考えられる。

以上を踏まえ，本報では被検查物上のき裂近傍で局 部加熱を行い,これをまたいだ 2 点間の温度差の測定 に基づく，熱的手法によるき裂深さの定量的な非破壊 評価について検証を行う。まずはじめに材料の一例と してステンレス鋼を用い，二次元スリットを対象とし た奉験を行い，スリット深さの評価を試みる，次に同 様の方法によるき裂深さの䚵価について検証する。き 裂を対象とした場合，スリットを対象とした場合とは 異なり，き裂面同上の接触の影響を考虑する必要があ る。そこで，伈力負荷によるき裂開い効果が温度予布 
に与える影響を検証し，適当な応力を負荷しき裂を開 山することにより，熱的手法によるき裂深さの評価が 可能となることを示す.

\section{2. 解 析}

図 1 に示すように材料表面上に存在する二次元垂直 き裂あるい仗スリットの深さを，熱的手法により評価 する問題を考える。図 1 のように材料表面上に原点を もつ直交座標系 $(x, y, z)$ を導入する. 図 1 は問題の 対称性上り解析対象とした $y$ 方向の $1 / 2$ なる領域を 表している．原点を中心とした直径 $D$ の阷領域 $\mathrm{S}$ にレーザビームの照射を行った場合の，集中熱流束 $q$ に上る局部加熱に起因する材料表面上の温度分布に注 目与る。

図1において， $L_{1}$ はモデルの半長，Wおよび $H$ は それぞれモデルの幅および厚さである。き裂あるいは スリットは深さ $a$ および有限幅 $b$ を有し，原点から $X$ の距離に位置するものとする。またbが十分に小 さく，温度分布に対し影響を与えないとみなせる場合 をき裂を刘侀としたモデルと考える。

本解析は非定常熱伝導問題の三次元有限要素法によ り行う。な㧍有限要素法解析には沨用有限要素法解析 システムABAQUS ver 5.6’在用いた。

\section{基礎方程式は}

$$
\frac{\partial \theta}{\partial t}=\frac{\lambda}{\rho C}\left(\frac{\partial^{2} \theta}{\partial x^{2}}+\frac{\partial^{2} \theta}{\partial y^{2}}+\frac{\partial^{2} \theta}{\partial z^{2}}\right) .
$$

ここで $\theta$ は温度, $\lambda$ は熱伝導率, $\rho$ は密度, $c$ 比比熱在 表す。初期温度 $\theta_{0}$ からの温度変化を $T$ で表せば

$$
T=\theta-\theta_{0}
$$

さらに温度伝学率 $\boldsymbol{x}=\lambda / \rho c$, 代表長さ $l$ 在導入し, 無 次元時間 $\tilde{t}$

$$
\tilde{t}=\kappa t
$$

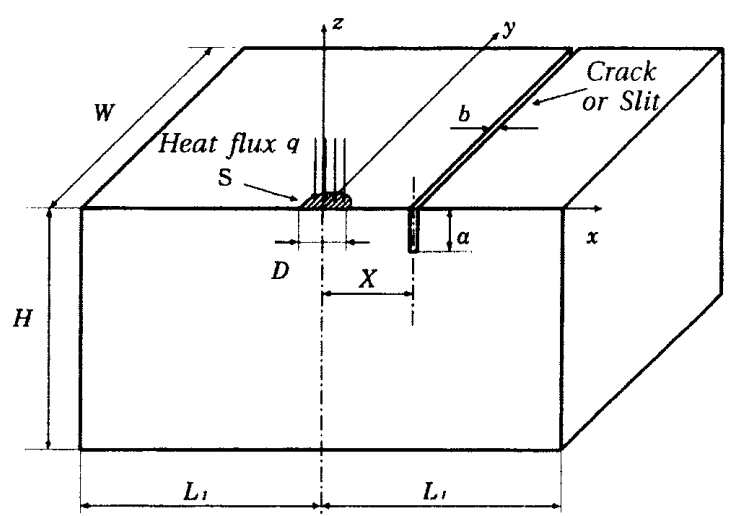

Fig. 1 Geometry of the analytical model
でまた無次元座標 $\tilde{x}, \tilde{y}, \tilde{z}$ をそれぞれ

$$
\tilde{x}=\frac{x}{l}, \quad \tilde{y}=\frac{y}{l}, \quad \tilde{z}=\frac{z}{l}
$$

で表す。 $\theta_{0}$ を一定とし， $\nsim$ は後述する実験の条件下に おいて温度によらず筀とみなすと, 式（1）は式(2)

〜 (4)を用いて次式のように変形できる.

$$
\frac{\partial T}{\partial \tilde{t}}=\frac{\partial^{2} T}{\partial \tilde{x}^{2}}+\frac{\partial^{2} T}{\partial \tilde{y}^{2}}+\frac{\partial^{2} T}{\partial \tilde{z}^{2}}
$$

以後の議論において, 代表長さを $l=1 \mathrm{~mm}$ とする.

境界条件については，加熱領域 Sでは熱流束一定の 境界条件とした。すなわち

$$
\frac{\partial T}{\partial \tilde{z}}=-\frac{q l}{\lambda} \quad \text { at } \quad \tilde{t} \geq 0
$$

な扔 $D$ につては後述する実験条件より $D=1 \mathrm{~mm}$ とした。 また後述する実験における温度変化において は熱伝導のみが支配的であると考元，S以外の表面に は次式で表される断熱条件を仮定した。

$$
\frac{\partial T}{\partial \tilde{n}}=0
$$

ここでれは表面における法線力向の無次元座標を表 す. 式(5)の解析結果は前記の仮定を満たす条件下で は，無次元時間にのみ支配され，異なる熱物性值を有 するあらゆる材料を評唒対象として考慮することがで き。

本解析では図 1 の解析領域を $L_{1}=20 \mathrm{~mm}, W=20$ $\mathrm{mm}, H=20 \mathrm{~mm}$ とした。非定常有限要素法解析にお ける訃算時間㧍よびメモリーの増大を考虑し，有限領 域を有するモデルに対する解析結果を，領域端に扔け る温度変化が十分に小さい時間領域においては, 解析 モデルの温度変化は領域端の影響を受けないとみな し，その時間領域に扔いて十分に半無限体モデルに対 する解析結果であるものとできる。き裂あるいはスり ットが存在しない場合, 寸なおち $a=0 \mathrm{~mm}$ の場合に 刘する数值解析の結果より, $i \leq 400$ 時間領域におい

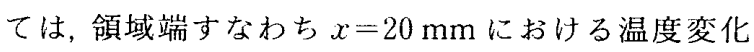
が, 加熱中心の温度変化に対し十分に小さいことから この解析領域を半無限体モデルとみなすものとする. 半無限体モデルを用いた解析結果はこれより大きな領 域を有する試験片を用いた笑験結果の評価に適肘する ものとする。また後述する実験に用いた胉さ5 mm なる試験片を対象に評洒を行うにあたっては，H=5 $\mathrm{mm}$ として有限板モデルを想定した数做解析を行い, その結果を用いた。

次にき裂幅あるいはスリット幅，すなわちb0解析 結果への影脊を考える。き裂深さの評価を行うにあた り，bの影響を受けないことが求められる。すなわち き裂を刘象とした数值解析の場合, 温度分布が $b$ の影 
響を受けないよう, $b$ を十分に小さくする必要があ る.そこで $a=5 \mathrm{~mm}, X=5 \mathrm{~mm}$ なる場合を想定し， $b$ を 0.2 から $0.0002 \mathrm{~mm}$ の範囲で変化させて数値解 析を行った。

図 2 に一例として $\tilde{t}=19.6$ なる場合における材料 表面上の $x$ 軸上, $x=4 \mathrm{~mm}$ から $5 \mathrm{~mm}$ に抢ける温度 変化分布の解析結果を示す。ここで $T_{a, x}$ は深さ $a$ の き裂あるいはスリットを有するモデルにおける $x$ 軸 上の点 $(x, 0,0)$ の温度変化を表すものとする. 図 2 よ り $b$ が $0.0002 \mathrm{~mm}$ なる場合の解析結果と $0.002 \mathrm{~mm}$ なる場合の解析結果を比較すれば, 違いは非常に小さ く無視することができる。これより $b$ が $0.0002 \mathrm{~mm}$ なる場合の解析結果では $b$ の影響を無視できるとい える. 以後, $b=0.0002 \mathrm{~mm}$ なる場合の解析結果をき 裂に対する数值解として用いるものと寸る。また $b$ が $0.0002 \mathrm{~mm}$ より十分に大きな幅を有する場合，す なわちスリットを評価の対象とした場合は，解析モデ ルの $b$ を実在のスリット幅と等しくする必要がある。 後述する実験に使用した $b$ が $0.4 \mathrm{~mm}$ なる二次元ス リットを有する試験片の評価を行うにあたっては， $b$ $=0.4 \mathrm{~mm}$ として数值解析を行い, その結果を用いた.

さらに材料表面上の温度変化の分布に注目して，き 裂が存在する場合と存在しない場合の比較を行う。き 裂を対象として $b=0.0002 \mathrm{~mm}, X=5 \mathrm{~mm}$ なる場合 を想定し, $a$ を 0 から $10 \mathrm{~mm}$ の範囲で変化させて, 半 無限体モデルに対する解析結果とみなせる $\tilde{t} \leq 40$ な る時間領域において数值解析を行った。

図 3 に, 材料表面上の $x$ 軸上の温度変化分布の一例 として $a=0,5 \mathrm{~mm}, \tilde{t}=19.6$ なる場合の解析結果を 示す. 図 3 は，材料表面上における温度変化へのき裂 の影響が，き裂開口部の加熱側で温度上昇として，ま た反対側で温度降下として現れることを示しており， き裂開口部に近づくほど顕著になることがわかる。ま たき裂面での断熱を仮定することにより，き裂が存在

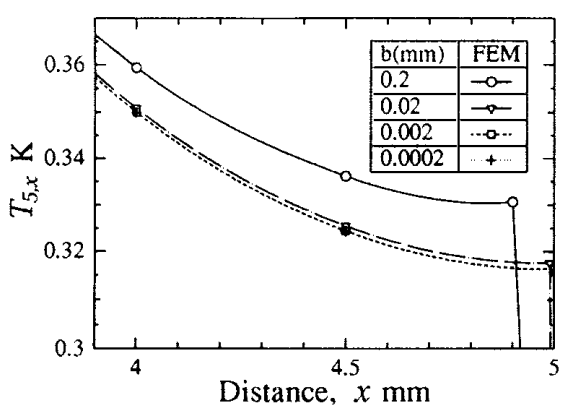

Fig. 2 Effect of the crack or slit width on temperature $(a=5 \mathrm{~mm}, X=5 \mathrm{~mm}, \tilde{t}=19.6)$
する $x=5 \mathrm{~mm}$ の位置で温度変化が不連続となること を示している.

以後，き裂あるいはスリットをまたぎ，その中心か ら等しい距離 $X^{\prime}$ なる 2 点間の温度変化の差, すなわ ち $\Delta T_{a, X \pm X}$ に着目する。き裂およびスリット染さの 評価パラメータとして $\Delta T_{a, x \pm x^{\prime}}-\Delta T_{0, X \pm x^{\prime}}$ を導入す ることも考えられるが，後述の実験において，境界条 件として用いるレーザ照射による熱流束は，レーザ出 力および材料表面における吸収効率によって影響され る末知なる定数であるため, $\Delta T_{a, X \pm X}-\Delta T_{0, X \pm X}$, の 大小によってき裂あるいはスリット深さを直接評価す ることはできない。そこでき裂あるいはスリットが存 在しないときの 2 点間の温度変化の差で無次元化し, $\Delta T_{a, X \pm X^{\prime}} / \Delta T_{0, X \pm X^{\prime}}$ をき裂およびスリット樑さの評価 パラメー夕とする。なお，初期温度が一定であること を仮定していることから， $\Delta T_{a, x \pm x^{\prime}}$ は式(2)より

$$
\Delta T_{a, x \pm x^{\prime}}=T_{a, x-x^{\prime}}-T_{a, x+x^{\prime}}=\theta_{a, x-x^{\prime}}-\theta_{a, x+x^{\prime}}
$$

であり，2 点間の温度差に等しい。ここで $\theta$ の添字は $T_{a, x}$ の添字と同様である.

\section{3. 実 験 方 法}

$3 \cdot 1$ 試験片 ワイヤカットにより導入した幅 $0.4 \mathrm{~mm}$ の二次元スリットを有する試験片(スリット 付試験片)を 3 本 (A-I，A-II，A-III) 用意した。各試 験片の寸法抢よびスリット深さを表 1 に示す。

また疲労き裂付試験片として試験片 B を用意した。

Table 1 Specimens with slit

\begin{tabular}{ll|c|c|c}
\hline \hline Specimen & & A-I & A-II & A-Ill \\
\hline Jength & $\mathrm{mm}$ & 250 & 250 & 250 \\
\hline Width & $\mathrm{mm}$ & 100 & 100 & 40 \\
\hline Thickness & $\mathrm{mm}$ & 50 & 50 & 40 \\
\hline Slit depth & $\mathrm{mm}$ & 5 & 3 & 2 \\
\hline
\end{tabular}

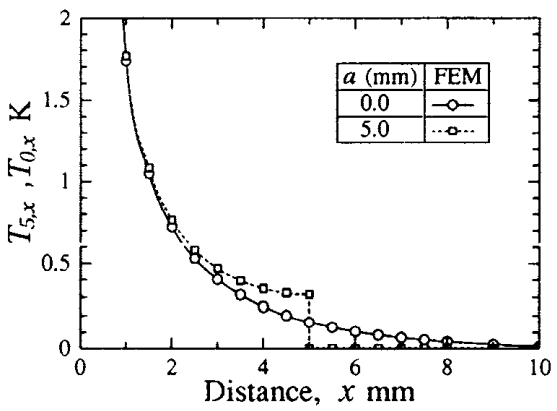

Fig. 3 Distribution of the variation of temperature on the surface $(a=0,5 \mathrm{~mm}, \quad \tilde{t}=19.6)$ 
試験片 B は図 4 に示すように長さ $200 \mathrm{~mm}$, 板厚 40 $\mathrm{mm}$, 板幅 $40 \mathrm{~mm}$ を有する. 同試験片に幅 $3 \mathrm{~mm}$, 深 さ $3 \mathrm{~mm}$ を有する $V$ 切欠きを導入後, スパン $180 \mathrm{~mm}$ の三点曲げにより最大荷重 $51.0 \mathrm{kN}$ ，応力比 0.05 , 周 波数 $5 \mathrm{~Hz}$ の条件にて疲労き裂を導入し, 図 4 の上部 の厚さ $5 \mathrm{~mm}$ の斜線部を切除した。この状態で温度 分布の計測を試みた後, 応力負荷によるき裂開口効果 がき裂面での熱伝導特性に与える影響を調べる月的 で、負荷を容易にするため，さらに図 4 の下部斜線部 を切除し，最終的な板愿が $5 \mathrm{~mm}$ なる図の带状の白い 部分を試験片とし，計測に供した。さらに計測終了後， 試験片を破断し，き裂深さを測定した，

なおいずれの試験片もオーステナイト系ステンレス 鋼(SUS 304)製であり，熱物性值を表 2 に示す。

$3 \cdot 2$ スリット付試験片に対する実験実験力法 の概略を図 5 に示す、試験片表面上の直径 $D=1 \mathrm{~mm}$ なる領域 Sに，Nd：YAGレーザによるレーザ照射を 行い, 熱流束 $q$ を供給し試験片を加熱した。加熱領域 の中心は試験片の幅方向の中心に配置した、スリット りない表面の温度分布を測定する場合は，加熱中心か ら長さ方向の $20 \mathrm{~mm}$ 以内の範囲に、スリット拉よび 試験片端が存在しない位置において加熱した。スリッ トの影響による温度分布の変化を測定する場合は, 加 熱中心から $X=5 \mathrm{~mm}$ なる位置にスリットを配置し， 加熱した。なお人りットおよび $3 \cdot 3$ 節で対象とする疲 労き裂は，それらの近傍の加熱により得られる熱画像 を観察することで，検出が可能であり，それらの位埴 および向きは既知である。

材料表面上の温度は赤外線画像装置を用いて測定し

Table 2 Thermal properties of 304 stainless steel

\begin{tabular}{l|c}
\hline Density & $7.92 \times 10^{3} \mathrm{~kg} / \mathrm{m}^{3}$ \\
\hline Thermal conductivity & $15.9 \mathrm{~W} /(\mathrm{m} \cdot \mathrm{K})$ \\
\hline Specific heat & $0.511 \times 10^{3} \mathrm{~J} /(\mathrm{kg} \cdot \mathrm{K})$ \\
\hline
\end{tabular}

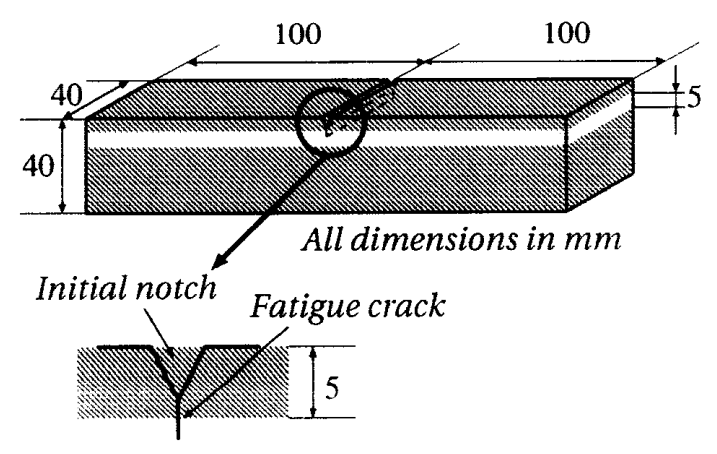

Fig. 4 Specimen B
た. 表 3 に実験に用いた赤外線画像装置の仕様を示 す. 同装固は最大 10 点まで点状領域の温度の時間計 測が可能であり, 加熱中心から $x$ 軸上 $x=0,2,3,4$, $6.7 \mathrm{~mm}$ なる点の温度計測を行った. 各点の温度を

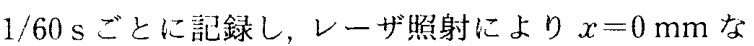
る点に扔ける $1 / 60 \mathrm{~s}$ 間の急激な温度上昇が現れる直 前の時刻を時間の原点とした。またそのときの各点の 温度の平均值を試験片の初期温度とした。各時間の温 度は，赤外線画像装置の測定ノイズによる影響をなく すため，前後 5 点の時間における温度の平均值を採用 した。

なお実験による温度計測に際し，図 5 に示すように， 試験片表面に市販のツヤなし黑色スプレーによるコー ティング処理を行った. 同処理は, 温度計測を行う材 料表面上の放射率を黑体と同一とみなし，またレーザ の吸収効率を向上させる目的で行った、コーティング 凮の厚さは、試験片の熱伝導に対する影響が無視でき る宁さとした。

$3 \cdot 3$ 疲労き裂付試験片に対する実験疲労き裂 を対象とした埸合，き裂面同士の接触の影響，すなわ ち熱伝導によりき裂面を通過する熱流束が存在するた め，き裂面に断熱の境界条件を仮定し評価を行うこと は，き裂深さを実際の値より小さく評価することにつ ながり危険である。そこでき裂開口效果によりき裂面 同:日接触の影蚃を除き，断熱境界条件を仮定するた め, 試験片 B に対し四点曲げによる応力負荷の条件下 で $3 \cdot 2$ 節と同様の実験を行った。なお温度の計測点と

Table 3 Main specifications of the infrared thermography

\begin{tabular}{c|c}
\hline \hline Temperature range & $273 \sim 773 \mathrm{~K}$ \\
\hline Sensitivity & $0.2 \mathrm{~K}$ \\
\hline Picture resolution & $256 \times 256$ \\
\hline Frame time & $1 / 60 \mathrm{sec}$ \\
\hline Field of view & $14^{\circ} \times 9^{\circ}$ \\
\hline
\end{tabular}

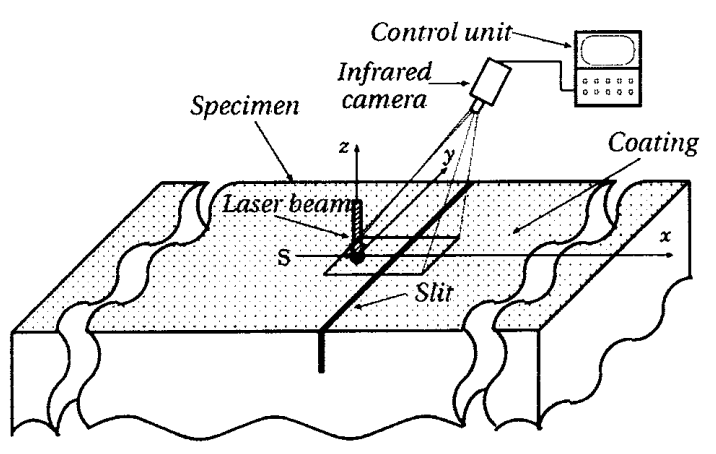

Fig. 5 Schematic diagram of the experimental setup 
して $3 \cdot 2$ 節に示した加熱中心から $x$ 軸上の $x=0,2$, $3,4,6,7 \mathrm{~mm}$ なる点に加え,さらにき裂近傍の点にお ける温度に注目し， $x=4.5,5.5 \mathrm{~mm}$ なる点の温度も計 測した。

\section{4. 実験結果および考察}

\section{4・1 スリット付試験片に対する結果および考察}

A-I，A-II，A-IIIなる各試験片について， $\tilde{t}=19.6$ すなわち加熱後 $t=5.0 \mathrm{~s}$ なる時刻における加熱中心か ら $x$ 軸方向の温度変化分布の実験結果と解析結果の 比較を図 6〜8に示す，各図において，スリットが存 在する場合およびスリットが存在しない場合の実験値 は，それぞれ同一のレーザ出力によって得られた実験 結果である。な控験值として，同一の加熱条件から なる 4 回の試行における平均値を用いた。また実験に おける境界条件の熱流束は未知であり，解析結果と実 験結果を直接比較することはできない，そこでスリッ トが存在しない場合について，温度变化の実験結果と 解析結果が合うようにし，これにより解析に用いた熱 流束を決定した。スリットが存在する場合の解析結果 は，このようにして決定した熱流束を用いて得られた 結果である.図6〜8において，スリットが存在する 場合抢よびスリットが存在しない場合ともに，温度変 化分布の実験結果と解析結果はよい一致を示してい

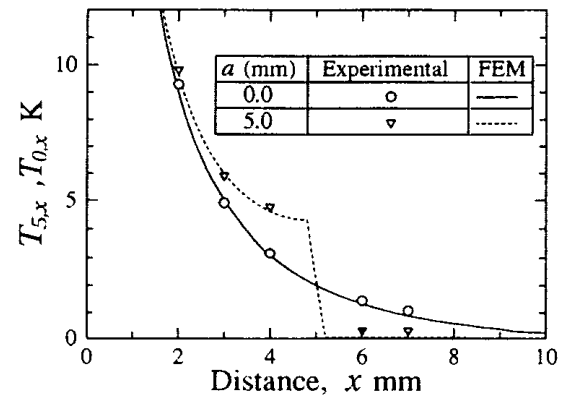

Fig. 6 Experimental results in comparison with finite element analysis for specimen $\mathrm{A}-\mathrm{I}$

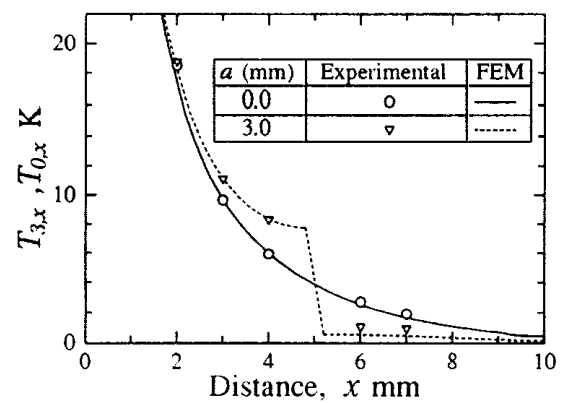

Fig. 7 Experimental results in comparison with finite element analysis for specimen A-II
る.このことは, $\Delta T_{a, X \pm X} / \Delta T_{0, X \pm X^{\prime}}$ によれば,スリ ットが存在する場合と存在しない場合において同一の 加熱条件であれば, 熱流束の測定が不必要であること を表している.さらに半無限体の解析モデルの使用が 妥当であり，またスりット面に断熱境界条件を課すこ とが適切であったことを表している。

図 9 に，スリット中心すなわち $X=5 \mathrm{~mm}$ より $x$ 軸 方向に $X^{\prime}=1 \mathrm{~mm}$ なる 2 点間の温度差を用いた場合 の $\Delta T_{a, X \pm X^{\prime}} / \Delta T_{0, X \pm X^{\prime}}$ の実験結果と解析結果の比較を

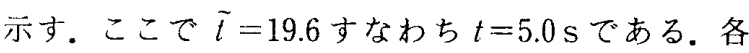
試験片に対し，レーザ出力を変化させそれぞれ 2 回の 評価を行った。図 9 より求めたスリット染さの評価結 果を表 4 に示寸. $\Delta T_{a, X \pm X^{\prime}} / \Delta T_{0, X \pm X^{\prime}}$ の実験結果と解 析結果はよい一致を示しており，同パラメー夕を用い

Table 4 Evaluated slit depths and the actual slit depths

\begin{tabular}{c|c|c}
\hline \hline Specimen & $\begin{array}{c}\text { Actual slit depth } \\
\mathrm{mm}\end{array}$ & $\begin{array}{c}\text { Evaluated slit depth } \\
\mathrm{mm}\end{array}$ \\
\hline A-I & 5.0 & 4.9 \\
\cline { 2 - 3 } & & 5.2 \\
\hline A-II & \multirow{2}{*}{3.0} & 3.1 \\
\hline \multirow{2}{*}{ A-III } & 2.0 & 2.9 \\
\hline
\end{tabular}

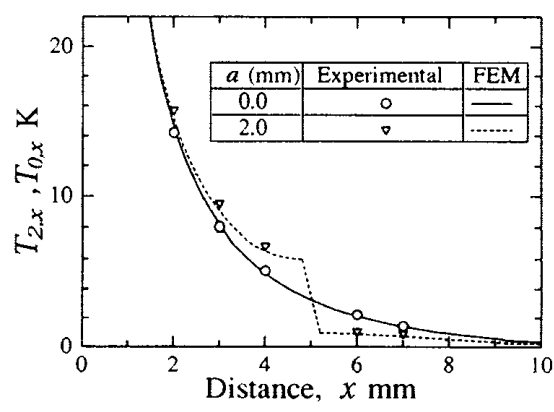

Fig. 8 Experimental results in comparison with finite element analysis for specimen A-III

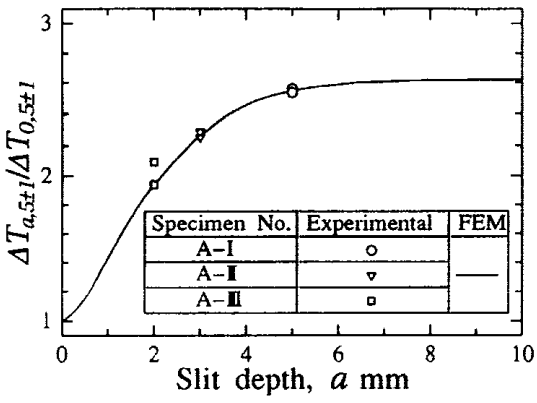

Fig. 9 Comparison of experimental values of the parameter for evaluating slit depths with finite element analysis 
ることにより，スリット深さの評価を良好に行うこと が可能であるといえる.

以.上より，スリット深さの評価を行うにあたり $\Delta T_{a, x \pm x} / \Delta T_{0, X+x}$ が有効であることが示された。

\section{$4 \cdot 2$ 疲労き裂付試験片に対する結果および考察}

試験片 Bについて疲労き裂を導入後, 図 4 の上部斜 線部を切除し計測を試みた。さ裂の検知については， 温度分布の不連続部の検出により可能であったが，き 裂哚さの評価は，き裂が存在する場合とき裂が存在し ない場合におけるき裂をまたいだ 2 点間の温度差の違

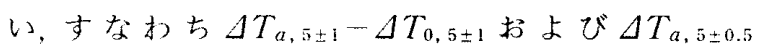
- $\Delta T_{0,5 \pm 0.5}$ が棌棌 $0.1 \mathrm{~K}$ と温度計測装置の表示分解 能と等しく， $\Delta T_{a, x_{ \pm} x^{\prime}} / \Delta T_{0, X_{ \pm} x^{\prime}} \approx 1$ であった.この ことは，き裂が閉じている場合，き裂面同士の接触に よる熱伝導の影策が大きく，き裂面での境界条件を断 熱とは仮定できないことを示しており，この值を用い てき裂梁さの評価を行うことはできない.

そこで四点曲げによる応力負荷を行い，き裂開口効 果がき裂面における熱伝導へ与える影響を検証した。 真荷を容易にするため試騟片Bの板厚最終的に 5 $\mathrm{mm}$ とした，孯さ $5 \mathrm{~mm}$ にした後の試験片 Bにお いては，切削の影莘によるものと照われるが無負街状

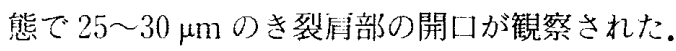

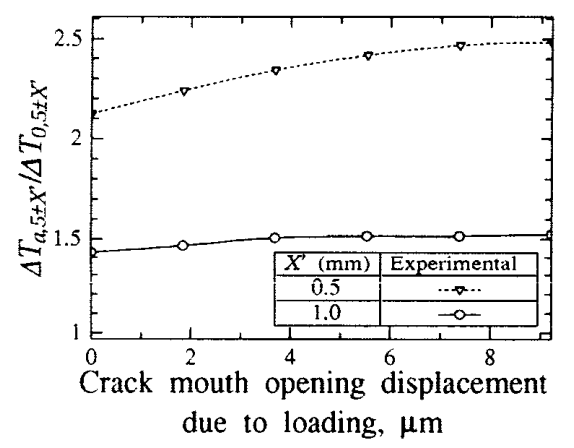

Fig. 10 Effect of the crack mouth opening displacement on the parameter for evaluating crack depth

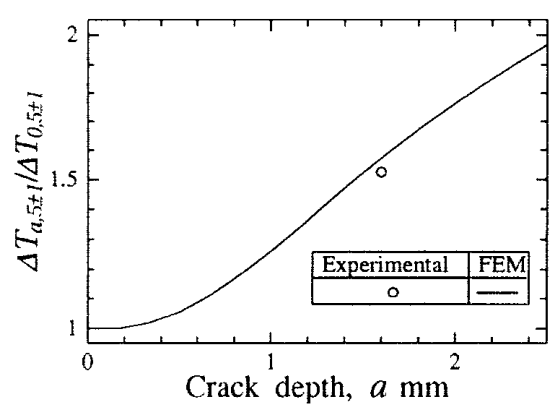

Fig. 11 Comparison of experimental value of the parameter for evaluating crack depth with finite element analysis $\left(X^{\prime}=1 \mathrm{~mm}\right)$
四点曲げによる応力負荷条件下における， $\tilde{t}=19.6$, $X^{\prime}=1,0.5 \mathrm{~mm}$ なる場合の $\Delta T_{a, X \pm X^{\prime}} / \Delta T_{0, x_{ \pm} x^{\prime}}$ の実験 結果を図 10 に示寸。ここで図 10 の横軸は, 応力負荷 による扇部でのき裂開口変位である(6).

図 10 より, 無負荷状態でも $\Delta T_{a, x \pm X} / \Delta T_{0, x \pm X^{\prime}}$ の 储が1より大きな値を示しているが，これは無负荷 状態に扔けるき裂の開口の影響と考えられる。ま た図10より，適当な応力負荷によるき裂開口に伴い $\Delta T_{a, X \pm X^{\prime}} / \Delta T_{0, X \pm X^{\prime}}$ の值が収束する様子が読取れる。

収束した值と解析結果の比較を図 11,12 にそれぞ れ示寸。また図 $11 ， 12$ より求めたき裂梁さの評価結 果, 扔よび試験片 B を破断し破面上で計測したき裂樑 さを比較して表 5 に示す。き裂深さが適切に評洒され ていることから，応力負荷によりき裂を開口させた場 合，き裂面同士:の接触の影響が除かれ，4・1 節と同様 にき裂面に断熱の境界条件を課した方法のき裂深さの 評価への適用が可能となることが示された。

\section{5. 結言}

本研究以波労き裂を対象として, 被検査物に対しレ ーザ照射による局部加熱を行うことにより生じる温度 分布を赤外線画像装置により測定することに基づくき 裂媣さの定量的非破壊評価について検証をしたもので ある、その結果, スリットを対象とした場合, き裂面 に断熱の境界条件を課すことにより十分な精度でスり ット深さの評価を行うことができた。

Table 5 Evaluated crack depth and actual crack depth observed on the fractured surface

\begin{tabular}{c|c|c}
\hline \hline Specimen & $\begin{array}{c}\text { Actual crack depth } \\
\text { mm }\end{array}$ & $\begin{array}{c}\text { Evaluated crack depth } \\
\mathrm{mm}\end{array}$ \\
\hline $\mathrm{B}$ & 1.6 & $1.5\left(X^{\prime}=1.0 \mathrm{~mm}\right)$ \\
\cline { 2 - 3 } & & $1.4\left(X^{\prime}=0.5 \mathrm{~mm}\right)$ \\
\hline
\end{tabular}

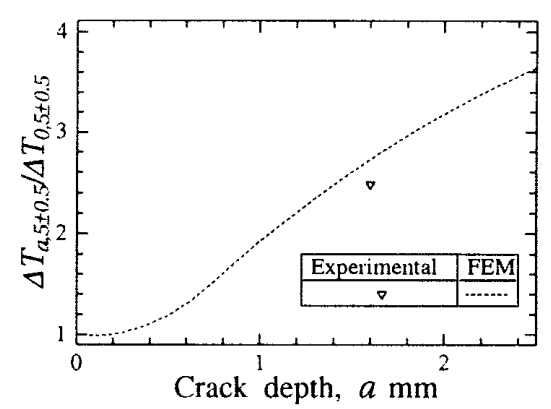

Fig. 12 Comparison of experimental value of the parameter for evaluating crack depth with finite element analysis $\left(X^{\prime \prime}=0.5 \mathrm{~mm}\right)$ 
一方で，疲労き裂すなわち閉じたき裂に対しては， き裂面同士の接触による熱伝導の影響が大きく，き裂 深さの評価を行うことは困難であった。しかしなが ら，応力を負荷しき裂を開口させることによりき裂面 の境界条件を断熱とみなすことができ，き裂深さの評 価への適用が可能となることを示した。

最後に，終始摡切丁寧なご指導をいただいた東北大 学, 阿部博之総長に深く感謝の意を表する.また本研 究における実験の一部は東北大学ベンチャー・ビジネ ス・ラボラトリーを利用して行われたことを記す。

\section{文}

\section{献}

（1）Banks, H.T., ほか 2 名, Boundary Estimation Prob- lems Arising in Thermal Tomography, Inverse Prob lems, 6-6(1990), 897-921.

(2) Spicer, J.W.M., 活か3 名, Measurement of Coating Physical Properties and Detection of Coating Disbonds by Time-Resolved Infrared Radiometry, J. Nondes. truct. Evaluat., 8-2(1989), 107-120.

（3）阪上隆英・小倉敬二, ジュール熱に上る瞬時加熱温度場 のサーモグラフィ計測に基づく非破壊欠踓計測，機論， 58-555, A (1992), 2224-2231.

（4）白鳥正樹・ほ加 2 名, 赤外線映像装置に上了き裂の検知 と画像处理, 機論, 58-556, A (1992), 2274-2279.

(5) Saka, M., ほか 2 名, NDE of a Crack by Using Closely Coupled Probes for DCPD Technique, Trans. ASME, J. Pressure Vessel Technol., 118-2(1996), 198-202.

（6）㣚村弘之, 線形破壊力学入門，(1976)，218，培風館. 